\title{
Unclassified Crystal Measurement
}

National Cancer Institute

\section{Source}

National Cancer Institute. Unclassified Crystal Measurement. NCI Thesaurus. Code C74757.

The determination of the amount of unclassified crystals present in a urine sample. 